\title{
The confessions of a justified sinner and the psychopathology of the double
}

\author{
Allan Beveridge, Consultant Psychiatrist, West Fife District General Hospital, \\ Whitefield Road, Dunfermline KY12 0SU
}

In discussions of the psychopathology of the double, acknowledgement is usually given to the various literary accounts of the subject by Dostoevsky, De Maupassant and Stevenson (Christodoulou, 1986). Curiously, mention is never made of the work that has been described by Karl Miller (1985) as "the cardinal text" in the literature of the double. James Hogg's The Private Memoirs and Confessions of a Justified Sinner, published in 1824 and since recognised as a Scottish literary classic, represents the most detailed and complex exploration of the theme of the double.

\section{The private memoirs and confessions of a justified sinner}

Set in early 18th century Scotland, Hogg's novel relates how a young man uses his belief in the Calvinist doctrine of predestination to justify the murder of his brother. The central character, Robert Wringhim, can be viewed as diabolically possessed or as clinically insane. His double, the mysterious GilMartin, who incites him to murder, can be seen as the incarnation of the Devil or as a symptom of Wringhim's diseased mind. The novel's power lies in the tension between these two conflicting interpretations. For the present purpose Wringhim will be considered to be mentally deranged.

The first evidence of Wringhim's mental instability occurs when, during a state of exalted spirits, he meets "a young man of mysterious appearance".

“... I felt a sort of invisible power that drew me towards him, something like the force of enchantment, which I could not resist... What was my astonishment, on perceiving that he was the same being as myself? The clothes were the same to the smallest item. The form was the same; the apparent age; the colour of the hair; the eyes; and ... the features too were the very same".

The mysterious young man, later revealed to be Gil-Martin, is to haunt Wringhim throughout the book and is to evolve from friend to persecutor.

Later in the novel, Wringhim's tenuous sense of self is further undermined when he becomes ill:

“... I generally conceived myself to be two people. When I lay in bed, I deemed there were two of us in it; when I sat up, I always beheld another person, and always in the same position from the place where I sat or stood, which was about three paces off me towards my left side ... over the singular delusion that I was two persons, my reasoning faculties had no power. The most perverse part of it was, that I rarely conceived myself to be any of the persons. I thought ... my companion was one of them, and my brother the other".

Subsequently Wringhim learns about deeds he has committed, of which he has no recollection. He is said to have seduced a young woman, dispossessed her mother and hired a new servant. Bewildered, he concludes:

"I was a being incomprehensible to myself. Either I had a second self, who transacted business in my likeness, or else my body was at times possessed by a spirit over which it had no control".

Wringhim's mysterious companion, Gil-Martin, is shown to possess amazing powers such as his capacity to transform himself into other people. As Wringhim relates: 'I observed several times, when we were speaking of certain divines and their tenets, that his face assumed something of the appearance of theirs ... he entered at once into their conceptions and feelings".

Gil-Martin explained his strange facility: "If I contemplate a man's features seriously, mine own gradually assume the very same appearance and character ... I attain to the possession of his most secret thought". Gil-Martin exercises total control over Wringhim, who admitted, "he had complete influence over me by night and day".

In addition to his fundamental belief in possessing a double, Wringhim displays other signs of derangement. He has an hallucinatory experience on Arthur's Seat, where he sees a woman "robed in white" and reprimanding him for attempting murder. In the later stages of his mental disintegration, he repeatedly hears voices, discussing him in a threatening manner, and he sees "hideous fiends" who attack him. His final act, under the influence of Gil-Martin, is to commit suicide by hanging himself.

\section{Commentary}

It will be evident that Hogg's novel explores the territory of the double with great sophistication. 
The experience of the double spills over into many areas of psychopathology and embraces perceptual, delusional and depersonalisation phenomena. It may take the form of the perception of one's own double, as in the experience of autoscopy; it may be the belief in the double of one's self, as in the syndrome of subjective doubles; or it may be the belief in the double of others, such as in the Capgras, Frégoli or intermetamorphosis conditions. The concepts of multiple personality and of the Doppelgänger also relate to the subject. The Confessions illustrates many of the elements of these psychopathological conditions.

For example, Wringhim gives an account of autoscopy when he describes seeing himself "three paces off me towards my left side". Wringhim also displays delusions about his self and claims to have "a second self, who transacted business" in his likeness. In the rare symptom of the autoscopic delusion, the subject has a fixed delusional belief in his separate concrete existence but no complementary perceptual experience. Wringhim certainly echoes this symptom in the later stages of the novel when he concludes that he has a double who commits crime in his name, but whom he has not seen. In the syndrome of subjective doubles, there is the belief that another person has been transformed into one's self and Wringhim comes close to this position at another stage in the novel when he considers that his brother or Gil-Martin have taken on his identity.

His shadowy tormentor, Gil-Martin, also serves as a very interesting illustration of several other psychopathological syndromes. In the Frégoli syndrome the patient feels that his persecutor can change faces, as the famous European actor Frégoli did on stage. GilMartin is held by Wringhim to have the ability of taking on the appearance of others. In the related syndrome of intermetamorphosis there is the belief that an individual is transformed both psychologically and physically into another. Gil-Martin's ability to adopt both the physical and mental attributes of another person has obvious similarities with this condition.

While it cannot be claimed that the precise definitions of particular syndromes are always fulfilled, the psychopathological terms themselves are often in Sims's (1988) eloquent opinion, "not precise points on the map of semantic space but indefinite smudges, not well localised".

In addition to his fundamental disturbance of identity, Wringhim also exhibits other symptoms of insanity. he hears voices, sees "visions" and has the delusion that he is controlled by another and although Bynum \& Neve (1985) have highlighted the pitfalls of diagnosing fictional characters, Wringhim's condition does bear a close resemblance to that of schizophrenia.

\section{Conclusion}

Bloedé (1988) has suggested that Hogg based his novel on the contemporary case of Mary Reynolds, who developed a second personality. It is also known that Hogg was acquainted with Dr Andrew Duncan and visited the Edinburgh Asylum in a spirit of serious inquiry. Whether the "Justified Sinner" had a real-life double, who resided at Morningside, remains unknown, as existing records provide no clues. Whatever the possible sources for the story, Hogg's work repays close reading by those with an interest in the psychopathology of the double.

\section{Acknowledgement}

I am grateful to Dr Gillian Hughes for her advice and information concerning James Hogg.

\section{References}

BLOEDE, B. (1988) A nineteenth-century case of double personality: a possible source for the confessions. In Papers given at the Second James Hogg Society Conference (ed. G. Hughes). Aberdeen: Association for Scottish Literary Studies.

BYNUM, W. F. \& NEVE, M. (1985) Hamlet on the couch. In The Anatomy of Madness, Vol. I (eds W. F. Bynum, R. Porter and M. Shepherd). London: Tavistock.

Christodoulou, G. M. (ed.) (1986) The Delusional Misidentification Syndromes. Basel: Karger.

Miller, K. (1985) Doubles: Studies in Literary History. Oxford: Oxford University Press.

Sims, A. (1988) Symptoms in the Mind: An Introduction to Descriptive Psychopathology. London: Bailliere Tindall.

Quotations from The Private Memoirs and Confessions of a Justified Sinner are taken from the 1983 Penguin edition. 